\title{
Enteral Nutrition In 6 Malaysian Intensive Care Units: A Point Prevalence Study of Prescription Practices
}

\author{
Azahar A, Ibrahim NA, Lim TA \\ Anaesthesiology Unit, Department of Surgery, Faculty of Medicine and Health Sciences, University Putra \\ Malaysia, Selangor, Malaysia
}

\section{ABSTRACT}

INTRODUCTION: Enteral nutrition (EN) is the first line of nutrition therapy for critically ill patients with an intact gastrointestinal tract. Even though intensive care units (ICUs) generally have established feeding protocols, prescribing practices to achieve nutrition goal is still widely variable among intensive care practitioners. The aim of this study was mainly to investigate commonly prescribed types and energy concentration in EN formulations including protein prescription. MATERIALS AND METHODS: This was an observational, point prevalence study, involving six level 3 ICUs in Malaysia. All patients aged type of EN formulation and protein prescription recorded. RESULTS: A total of 109 patients were included in the analysis out of which $78 \%$ of them were mechanically ventilated. At the point of the study, more than 16 years of age in the participating ICUs on the $11^{\text {th }}$ of October 2016 were enrolled in this study and $71.5 \%(78 / 109)$ received EN. Among the EN group, $68 \%(53 / 78)$ received standard formulation feeds $(1 \mathrm{kcal} / \mathrm{ml})$ while the rest received energy dense formulation $(>1 \mathrm{kcal} / \mathrm{ml})$. Fluid restriction was the main indication for energy dense formulation prescription, occurring in almost all (24/25) of the patients. There was no report of feeding intolerance. Only $2 / 109$ received parenteral nutrition (PN) giving the $E N$ to $P N$ ratio of 30:1. The mean protein prescription was $0.9 \mathrm{~g} / \mathrm{kg}$ (SD \pm 0.4). CONCLUSION: Prescription of EN was 30 times more frequent than PN in these ICUs. In those receiving EN, standard formulation feed was 3 times more commonly prescribed than energy dense feeds with fluid restriction being the main indication of the latter. Protein prescription was less than the guideline recommendation.

KEYWORDS: enteral nutrition, prescription practices, intensive care, standard formulation feeds, energy dense feeds

\section{INTRODUCTION}

Providing nutrition is essential in managing the critically ill patient. It prevents exacerbation of preexisting malnutrition and wasting of lean body mass as these patients are typically in catabolic state evidence by systemic inflammatory response and multiorgan dysfunction. Initiation of nutrition has changed from an adjunctive therapy for maintenance of homeostasis thus modulating of immune response and preventing oxidative cellular injury. ${ }^{1,2,5}$

Corresponding Author:

Dr. Aizad Azahar

Unit Anestesiologi, Fakulti Perubatan dan Sains

Kesihatan,

Universiti Putra Malaysia

Serdang, 43400 Selangor. Malaysia

Tel No : +60389472486

Email: aizadazahar@upm.edu.my
Enteral nutrition (EN) is defined as nutrition provided through the gastrointestinal tract via a tube or stoma that delivers nutrient distal to the oral cavity. Among the reported advantages of EN include modulation of stress responses, maintenances of gut integrity, attenuation of disease severity and for stress ulcer prophylaxis. The European Society for Parenteral and Enteral Nutrition (ESPEN) in 2016 recommends starting EN in patients who are not expected to be on a full oral diet within 48 hours of admission as dangerous depletion of lean tissue may occur after 14 days of starvation. ${ }^{3}$ These critically ill patients also may be at risk of malnutrition after a 48 hours of hospital stay. ${ }^{3}$ A meta-analysis of 12 trials in 2009, showed significant reductions in infection morbidity when early enteral nutrition was started on average within 36 hours of ICU admission. ${ }^{4}$ An updated metaanalysis of 21 randomized control trials in 2016, 
comparing the provision of early EN versus delayed EN demonstrated that provision of early nutrition was associated with a significant reduction in mortality and infectious morbidity. ${ }^{5}$

The energy requirement for prescription of nutrition is ideally calculated via measured energy expenditure using indirect calorimetry. Weight based formula (20-25 kcal/g/day) and other formula based on resting energy expenditure e.g., Harris Benedict Equation that may be used as a guide. ESPEN 2018 recommends that in any critically ill mechanically ventilated patients, energy expenditure should be determined by using indirect calorimetry ${ }^{3}$. If indirect calorimetry is not available, the measurement of exhaled carbon dioxide (VCO2) from the ventilator can be obtained to calculate the resting energy expenditure (REE) is recommended as it is more accurate than the weight base formula. ${ }^{3}$ Despite the accuracy, these devices is not widely available, thus simpler method of weight base formula is preferred among local clinicians with risk of inaccuracy in prescribing. ${ }^{6,7}$ An international survey on nutritional practices conducted in 167 ICUs across 37 countries, $69 \%$ received EN alone, and while mean daily energy prescribed was $24 \mathrm{kcal} / \mathrm{kg} /$ day, only a mean of $14 \mathrm{kcal} / \mathrm{kg} /$ day was delivered. ${ }^{8}$

To achieve EN goals early in a feeding intolerant patient, the use of promotility drugs, intravenous erythromycin with or without combination intravenous metoclopramide may be initiated. ${ }^{9}$ Small intestinal feeding or post pyloric feed is another method that can be introduced but require local expertise. ${ }^{10}$ Alternatively, energy delivery can be hastened to achieve early EN goals using an energy dense feed $(>1 \mathrm{kcal} / \mathrm{ml}) .{ }^{11,12}$

A point prevalence study of EN prescription practices done in 38 ICUs in Australia and New Zealand in the year 2012 with a total of 522 patients showed $40 \%$ of those patients received EN with near equal distribution of patient receiving standard feeding $(1 \mathrm{kcal} / \mathrm{ml})$ and energy dense feeding $(>1 \mathrm{kcal} / \mathrm{ml})^{13}$ In Malaysia data on EN prescription practices is still limited, especially among critical care patients.

A single day point prevalence study was held on the $11^{\text {th }}$ of October 2016 in six different tertiary hospital ICUs. The main purpose of this study was to investigate the prescribing practices of providing EN in critically ill patients. Additional data on types of
EN, indication for energy dense feeds, semielemental feeds and parenteral nutrition were also collected. The primary aim was to determine the types of EN most commonly prescribed by the intensive care doctors in Malaysia. In addition, we would like to determine the proportions of patients on EN were prescribed on energy dense or semielemental formula with their indications. Patients on PN were also collected with their indications. We hypothesized that EN is more commonly prescribed than PN, with frequent use of standard formula compared to energy dense formula.

\section{MATERIALS AND METHODS}

Six tertiary level ICUs audit participated in this study. Approval was obtained from the relevant authority and research ethics committee of each hospital. It was an observational point prevalence audit on the chosen date of 11 th October 2016. All adult patients (more than 16 years old) who were in the ICUs at that point of the day were recruited. This study was approved by Malaysia Research Ethical Committee (NMRR-16-1251-31432). Informed consent was waived as this study was observational in nature.

Surveillance information attained were patient's demographic (age, gender, weight, height). Source of admission, admission diagnosis, days of hospital admission, simplified acute physiology score (SAPS II) and sequential organ failure assessment score (SOFA) on admission and whether the patient was on invasive or non-invasive ventilation.

Specific information on EN includes the number of patients on EN, methods of EN delivery, days of EN, formula (brand) of EN. Also obtained were the divisions of patients receiving standard formula, dense energy formula and semi-elemental formula with each of their indications and prescribed protein.

\section{Statistical Analysis:}

The prevalence of patients on EN was described by descriptive analysis in each of the EN characteristic. Variables were reported as mean (SD) and median as appropriate. Formal sample size was not calculated as the objectives were descriptive in nature. However, to represent a usual clinical practice, sample sizes of at least 100 are believed to be 
Table 1. Patient information

\begin{tabular}{|c|c|c|c|}
\hline & $\begin{array}{l}\text { Total } \\
\text { Patients } \\
\text { Recruited }\end{array}$ & $\begin{array}{l}\text { Enteral } \\
\text { Nutrition }\end{array}$ & $\begin{array}{l}\text { Parenteral } \\
\text { Nutrition }\end{array}$ \\
\hline $\begin{array}{l}\text { No. of } \\
\text { patients }\end{array}$ & 109 & 78 & 2 \\
\hline $\begin{array}{l}\text { Mean Age, } \\
\text { Years (SD) }\end{array}$ & $\begin{array}{l}50.7 \\
(S D \pm 17)\end{array}$ & $49(S D \pm 18)$ & $70(S D \pm 17)$ \\
\hline Male Sex (\%) & $65 \%$ & $63 \%$ & $50 \%$ \\
\hline $\begin{array}{l}\text { Mean Weight, } \\
\text { Kg (SD) } \\
\text { Source of } \\
\text { Admission (\%) }\end{array}$ & $\begin{array}{l}68.6 \\
(S D \pm 17)\end{array}$ & $\begin{array}{l}68.2 \\
(S D \pm 16)\end{array}$ & $\begin{array}{l}58.5 \\
(S D \pm 17)\end{array}$ \\
\hline $\begin{array}{l}\text { Emergency } \\
\text { Department }\end{array}$ & $52.2 \%$ & $53 \%$ & \\
\hline Ward & $46.7 \%$ & $46 \%$ & $100 \%$ \\
\hline $\begin{array}{l}\text { Hospital } \\
\text { transfer }\end{array}$ & $1 \%$ & $1 \%$ & \\
\hline $\begin{array}{l}\text { Median } \\
\text { Hospital Stay, } \\
\text { Days }\end{array}$ & 7 & 7 & 9 \\
\hline $\begin{array}{l}\text { Mean SAPS II, } \\
\text { no. (SD) }\end{array}$ & $\begin{array}{l}42.5 \\
(S D \pm 20)\end{array}$ & $44\left(\mathrm{SD}_{ \pm} 19\right)$ & $46(S D \pm 19)$ \\
\hline $\begin{array}{l}\text { Mean SOFA, no. } \\
\text { (SD) }\end{array}$ & $7.8(S D \pm 4)$ & $8.3(S D \pm 4)$ & $9.5(S D \pm 4)$ \\
\hline \multicolumn{4}{|l|}{ Ventilation (\%) } \\
\hline Invasive & $78 \%$ & $88 \%$ & $100 \%$ \\
\hline Non-Invasive & $0.05 \%$ & $1 \%$ & \\
\hline Mask & $17 \%$ & $11 \%$ & \\
\hline $\begin{array}{l}\text { Median Feeding } \\
\text { Days, Days }\end{array}$ & 5 & 5 & 4 \\
\hline
\end{tabular}

SOFA = Sequential Organ Failure Assessment, SAPS II = Simplified Acute Physiology Score

enough. Information was collected in Excel Format and were analysed using IBM SPSS Statistics. Results were reported by descriptive statistic.

109 patients from six tertiary ICUs in peninsular Malaysia were enrolled. Patient characterizations were as per Table 1 with the youngest and oldest were sixteen and eighty-three, predominantly male. Mean weight was $68.2 \mathrm{~kg}(\mathrm{SD} \pm 17.8)$, with the highest was $160 \mathrm{~kg}$ whom was on non-invasive ventilation and was kept nil by mouth. On the day of the study 85 out of 109 patients (78\%) of patient were mechanically ventilated, while $5(0.05 \%)$ were put on non-invasive ventilation. There was a near equal distribution from source of admission with 57 (52\%) of patients were admitted from the emergency department and 51 (46.7\%) were from ward transfer.

Looking into EN, 68 out of $85(80 \%)$ mechanically ventilated patients were prescribed on EN. However, a total $19(17 \%)$ of patients were kept nil
Table 2: Charateristics of patients on EN

\begin{tabular}{|c|c|c|}
\hline & $\begin{array}{l}\text { Standard } \\
\text { formula } \\
(1 \mathrm{kcal} / \mathrm{ml})\end{array}$ & $\begin{array}{l}\text { Dense Energy } \\
\text { Formula } \\
(>1 \mathrm{kcal} / \mathrm{ml})\end{array}$ \\
\hline No. of patients & $53(68 \%)$ & $25(32 \%)$ \\
\hline Mean Age, Years (SD) & $49(S D \pm 15)$ & $52(S D \pm 17)$ \\
\hline Male Sex (\%) & $60 \%$ & $80 \%$ \\
\hline Mean Weight, Kg (SD) & $65(S D \pm 16)$ & $70(S D \pm 13)$ \\
\hline \multicolumn{3}{|l|}{ Source of Admission (\%) } \\
\hline $\begin{array}{l}\text { Emergency } \\
\text { Department }\end{array}$ & $51 \%$ & $52 \%$ \\
\hline Viard & $49 \%$ & $44 \%$ \\
\hline Hospital transfer & $0 \%$ & $4 \%$ \\
\hline $\begin{array}{l}\text { Median Hospital Stay, } \\
\text { Days }\end{array}$ & 6 & 7 \\
\hline Mean SAPS II, no. (SD) & $41(S D \pm 18)$ & $54(S D \pm 17)$ \\
\hline Mean SOFA, no. (SD) & $8(S D \pm 4)$ & $10(S D \pm 4)$ \\
\hline \multicolumn{3}{|l|}{ Ventilation ((\%) } \\
\hline Invasive & $87 \%$ & $92 \%$ \\
\hline Non-Invasive & $2 \%$ & $0 \%$ \\
\hline Mask & $11 \%$ & $8 \%$ \\
\hline $\begin{array}{l}\text { Median Feeding Days, } \\
\text { Days }\end{array}$ & 4 & 6 \\
\hline
\end{tabular}

by mouth on the day of the study, with multiple indications that were not recorded. When comparing types of feeds, 53 out 78 patients $(68 \%)$ were given standard formula $(1 \mathrm{kcal} / \mathrm{ml})$, while 25 patients $(32 \%)$ were prescribed dense energy formula $(>1 \mathrm{kcal} / \mathrm{ml})$. Table 2 described in the characteristics of the patients being prescribed on EN comparing standard formula which include semi-elemental and dense energy formula. Among the EN formula used in these intensive care units Novasource were the most prescribed ( 25 out of $78,32 \%$ ) and it was the only formula that being prescribed in the dense energy formula group. Variation of formula was seen in the standard formula group with Ensure being the most prescribed ( 23 out of $78,29 \%$ ).

Indications for starting dense energy formula was mainly for fluids restriction purposes (24 out of 25, $98 \%$ ), while the remaining patient were prescribed on dense energy formula because of hypernatremia. On that day none of the patients on dense energy formula were due to achieving early EN goals with the background of intolerance to standard energy formula. 
Table 3. Types of enteral nutrition prescribed

\begin{tabular}{llll}
$\begin{array}{l}\text { Standard formula } \\
(1 \mathrm{kcal} / \mathrm{ml}) \mathrm{n}=53 \\
(68 \%)\end{array}$ & & $\begin{array}{l}\text { Dense Energy } \\
\text { Formula } \\
(>1 \mathrm{kcal} / \mathrm{ml})\end{array}$ & \\
$\begin{array}{l}\mathrm{n}=25(32 \%) \\
\text { Formulation }\end{array}$ & $\begin{array}{l}\text { No. (\%) } \\
\text { Formulation }\end{array}$ & No. (\%) \\
Ensure & $23(29 \%)$ & $\begin{array}{l}\text { Novasource } \\
(2 \mathrm{kcal} / \mathrm{ml})\end{array}$ & $25(32 \%)$ \\
Nutrien diabetic & $13(17 \%)$ & \\
Glucerna & $10(13 \%)$ & \\
Optimax & $3(3.8 \%)$ & \\
Jevity & $2(2.6 \%)$ & \\
Semi-elemental & & \\
Peptamen & $2(2.6 \%)$ & \\
\hline
\end{tabular}

The EN: PN ratio was 30:1 with 2 out of 2 patients that were prescribed on parenteral nutrition were on bowel rest post intraabdominal surgery. None was reported due to intolerance to EN.

\section{DISCUSSION}

Our point prevalence study suggests that most of adult ICU patients $(72 \%)$ received EN on the day of study. Out of these, standard formula was more frequently prescribed as compare to dense energy formula $(68 \%$ vs $32 \%)$. For standard formula $E N$, the types of formulation were mainly based on each individual hospital protocol, but mainly given to tailored towards glycaemic control and feeding intolerance. Unfortunately, the method of calorie prescription was not captured on that day, but we assume that calorie prescription was mainly from the simplistic weight base equation due to ease of use with each patient being prescribed up to $25-30 \mathrm{kcal} /$ $\mathrm{kg} /$ day. Applicability of indirect calorimetry may be limited by institution availability and cost.

As with protein, the prescription in these sets of critically ill patients is lower than being recommended. From the data above, mean prescription was $0.9 \mathrm{~g} / \mathrm{kg}(S D \pm 0.2)$. Despite the weak evidence, there is a strong consensus from ESPEN 2016 recommending protein prescription of up to $1.3 \mathrm{~g} / \mathrm{kg} /$ day progressively in the critically ill patients3. Protein is the most important macronutrient in wound healing, supporting immune function and maintaining lean body mass.14 During the first day of sepsis protein synthesis is severely diminished while protein breakdown is greatly increased.15 ICU related diseases such as sepsis, trauma, and surgery added in with contributing comorbidities leads to a high degree of inflammatory process whereby it causes higher circulating cytokines, activating protein catabolism.16 The increased in proteolysis in critical illness causes muscle loss up to $1 \mathrm{~kg} / \mathrm{day}$, which can turn to the complications of ICU acquired weakness.17 A cohort study of 801 patients from 2004 - 2012 showed for each $1 \mathrm{~g} / \mathrm{kg}$ increase in daily protein delivery, the 90 days post-discharge mortality is reduced by $17 \% .18$ However, a higher level of intake $(1.9 \mathrm{~g} / \mathrm{kg})$ did not improve the protein -sparing effect.19 In a retrospective study of 455 patients it was suggested that although overall low protein intake is associated with the highest mortality, high protein intake $(1.2 \mathrm{~g} / \mathrm{kg} /$ day $)$ during the first 3-5days of ICU stay is also associated with increased long term mortality.20 Therefore, although care must be given in the intake of protein, the timing of intake might need to be considered during the prescription of protein for the critically ill.

88.9\% of patients on EN in this study were being given through bolus methods (A feed for every 3 hours) and $10 \%$ were on continuous infusion. ESPEN 2016 recommends switching bolus feeding to continuous feeds in high risk patients or those who shows intolerance 3 . Few small RCT comparing bolus and continuous infusion have shown fewer interruption in the delivery of enteral nutrition with continuous feeds, but no significant difference in outcome21,22 except these patients on bolus feeding reached the prescription goal faster by day 7.23 In terms of glycaemic control a randomised control trial involving 50 patients did not demonstrate clinically relevant differences between insulin use and glycaemic variability between bolus vs continuous EN.24

A total of $32 \%$ of patients being prescribed on dense energy feeding. Most were being given for the indication of volume restriction while maintaining full energy goals. The patient was usually prescribed on dense energy feeding based on their premorbid or due to single or multiple organ damage. There were no reported data on using dense energy feeding to hasten the achievement of calorie target in patient with intolerance to standard formula feeds. Feeding intolerance can be determined by physical examination, including abdominal examination, passage of flatus and stool and 
radiological evaluation (abdominal film). Suggestion of intolerance are vomiting, abdominal distension with discomfort, high nasogastric output, high gastric residual volume (ESPEN recommendation > $500 \mathrm{mls}$ ), diarrhoea, constipation and presence of dilated bowel in abdominal film. As intolerance leads to cessation feeds, exacerbation of ileus can be complicated with frequent and long periods of cessation.25 Besides prescription of promotility drugs (metoclopramide and erythromycin) and post gastric feeding, prescription of energy dense feeding $(>1 \mathrm{kcal} / \mathrm{ml}$ ) can be recommended especially for the volume intolerance patient. In a paediatric study it was shown that the prescriptions of dense energy feeding to increase energy delivery in a small group of non- critically ill children were successful. However, it remained to be certain whether early enhancement of energy delivery will contribute to a general reduction in morbidity and mortality. 26

The prescription of parenteral nutrition (PN) in this study was mainly due to post intraabdominal surgery, in which patient was put in bowel rest. No data reported for initiation of PN due to enteral feeding intolerance. Our study shows an EN to PN ratio of 1:30. Guidelines from ESPEN 2016 suggested that supplementary PN can be prescribed within three days of inability to meet more than $60 \%$ of energy and protein goals by enteral nutrition alone and must be weighed on a case by case basis. 3 All measures must be attempted to maximize EN tolerance before the decision to start on PN.

This study has pointed out that up to $71.5 \%$ of patients admitted to the ICU were being fed via EN. The main outcome measure from this point prevalence study is to understand better prescription practices among ICU caregivers in Malaysia. With this preferential technique of prescribing nutrition to critically ill patients, more emphasized should be placed on optimization of EN. This will ensure target energy and protein requirements were met and caloric balance is maintained in all critically ill patients.

Prescribing EN is more practical and safer as compared to PN. The most consistent outcome in comparing EN over PN is the reduction in infectious morbidity with two meta-analyses show a greater reduction in infectious morbidity when comparing EN over PN.27-28

\section{Study Limitations}

The study poses several limitations; among were, the patient sole nutrition prescription of that day was captured despite the patient may be on several other EN/ PN prescription during the entire ICU stay depending on the stages of his/her illness. The study also did non examined patients with feeding intolerance, which can contribute to the number of patients being put on nil by mouth during study day or were prescribed on PN. EN prescription was also may be limited by the risk of refeeding syndrome and nutrition risk as assessed by NUTRIC or NRS 2002 scores which were not reported in this study. Another limitation was the estimation of protein intake which was mainly based on the calculations of the protein content of the EN prescribed at the time of observation. Data on the supplemental protein was not recorded.

The result from this study may not be appropriate to other ICUs especially in non-tertiary hospital as their hospital may not have enough equipment such as feeding bags thus making their feeding protocol limited to bolus delivery. This point prevalence study is a random snapshot of prescription practices which does not represent the general practices in our hospital critical care settings. Nevertheless, the result of this study has identified the variation of enteral feeding prescribed in 6 Intensive care units in Malaysia. This information is important, as these findings will support future research in evaluating optimal nutrition delivery and its outcome.

\section{CONCLUSION}

This point prevalence study proposes that enteral nutrition was overwhelmingly more common than parenteral nutrition among critically ill patient with the EN: PN ratio of 30:1. Standard formulations EN were more frequently administered as compared to dense energy feeding. However, despite the prescription of dense energy EN may have a role in meeting early energy goals especially in feeding intolerance; we were unable to provide any data on this practice in this study.

\section{Competing interests:}

None declared. 


\section{ACKNOWLEDGMENT}

We wish to thank various people for their assistance in facilitating the study namely Datuk $\mathrm{Dr}$ Lim Chew Har, Hospital Pulau Pinang, Dr Lim Wee Leon, Hospital Sungai Buloh, Dr Kamarul Zaman Bin Talib, Hospital Serdang, Dato' Dr Jenny Tong May Geok, Hospital Tuanku Jaafar Seremban, Dr Zalina Abd Razak, Hospital Putrajaya and Dr Tai Li Ling, Hospital Kuala Lumpur.

\section{REFERENCES}

1. Nicolas Mongardon, Mervyn Singer. The Evolutionary Role of Nutrition and Metabolic Support in Critical Illness. Critical Care Clinics July 2010, 26(3): 443 - 450

2. Katri Peuhkuri, Heikki Vapaatalo, Riitta Korpela, Even low-grade inflammation impatcs on small intestinal function. World $\mathrm{J}$ Gastroenterology 2010, 16(9): 1057 - 1062

3. Pierre Singer, Annika Blaser, Mette M. Berger, Waleed Alhazzani et al; ESPEN guideline on clinical nutrition in the intensive care unit, Clinical Nutrition Aug 2019, 38: 48-79

4. Marik PE, Zaloga GP, Early enteral nutrition in acutely ill patients: a systemic review. Crit Care Med. 2001; 29(12):2264-2270

5. Stephen A. McClave MD; Beth E. Taylor, RD, DCN; Robert G Martindale, MD, PhD, Malissa M. Wrren et at; Guidelines for the Provision and Assessment of Nutrition Support Therapy in the Adult Critically III Patient: Society of Critical Care Medicine (SCCM) and American Society for Parenteral and Enteral Nutrition (A.S.P.E.N), Journal of Parenteral and Enteral Nutrition, Vol 40 (2), Feb 2016: 159-211

6. Oren Zusman, Ilya Kagan, Itai Bendavid et al. Predictive equations versus measured energy expenditure by indirect calorimetry: A retrospective validation. Clinical Nutrition June 2019, Volume 38(3): $1206-1210$

7. David C. Frankenfield, Abigail Coleman, Shoaib Alam, Robert N. Cooney. Analysis of estimation methods for resting metabolic rate in critically ill adults. Journal of Parenteral and Enteral Nutrition Oct 2008, Volume 33(1).

8. Albeda C, Gramlich L, Jones N, et al. The relationship between nutritional intake and clinical outcome in critically ill patients: result of an international multicentre observational study. Intensive care med 2009; 35: 1728-37
9. Lewis K, Alqahtani Z, Mclntyre L, Almenawar $S$, Alshamsi F, Rhodes A, et al. The efficacy dan safety of prokinetic agents in critically ill patients receiving enteral nutrition: a systemic review and meta-analysis of randomised trials. Critical Care June 2016 Vol 27: 259-278.

10. White H, Sosnowski K, Tran K, Reeves A, Jones $M$. A randomised controlled comparison of early post pyloric versus early feeding to meet nutritional targets in ventilated intensive care patients. Critical Care November 2009; Vol 13(6): R187

11. The TARGET investigators, for the ANZICS Clinical Trial Group. Energy Dense versus Routine Enteral Nutrition in Critically ill. The New England Journal of Medicine 2018; 379:1823-1834

12. Alberda C, Gramlich L, Naomi J et al. The relationship between nutrional intake and clinical outcomes in critically ill patients: results of an interational multicentre observational study. Intensive Care Medicine 2009; 35:1728- 1737

13. Sandra L Peake, Marianne J Chapman, Andrew R Davies, John L Moran, Stephanie O'Connor, Emma Ridley, Patricia Williams on behalf of the George Institute for Global Health and the Australian and New Zealand Intensive Care Society Clinical Trials Group; Enteral Nutrition in Australian and New Zealand Intensive Care Units: A Point-Prevalence Study of Prescription Practices; Critical Care and Resuscitation Vol 14, June 2012: 148-153

14. Stephen A. McClave MD; Beth E. Taylor, RD, DCN; Robert G Martindale, MD, PhD, Malissa M. Wrren et at; Guidelines for the Provision and Assesment of Nutrition Support Therapy in the Adult Critically III Patient: Society of Critical Care Medicine (SCCM) and American Society for Parenteral and Enteral Nutrition (A.S.P.E.N), Journal of Parenteral and Enteral Nutrition, Vol 40 (2), Feb 2016: 159-211

15. Vary TC, Voisin L, Cooney Rn. Regulation of peptide-chain initiation in muscle during sepsis by interleukin 1 receptor antagonist. Am J Physiol, 27 (1996): E513-E520.

16. Friedrich O, Reid M.B., Van den Berghe G., Vanhorebeek I., Hermans G., Rich M.M., Larsson L., The sick and the weak: Neuropathies/ myopathies in the critically ill. Physiol. Rev. Vol 95, 205: 1025-1109. 
17. Puthucheary ZA, Rawal J, McPhail M, Connolly $B$, Ratnayake $G$ et al, Acute skeletal muscle wasting in critical illness, JAMA 2013; 330:1591- 1600.

18. Peter J.M Weijs, Kris M. Mogensen, James D. Rawn, Kenneth B. Christopher, Protein intake, nutritional status and outcomes in ICU survivors: A single center cohort study, Journal of Clinical Medicine, Vol 8(1): 43, Jan 2019: 3-9

19. Plan LD, Hill GL. Energy balance in critical illness. Proc Nutr Soc, 62 (2003): pp 545-552.

20. Koekkoek W.A.C., Van Setten C.H., Laura E. Olthof, Kars J.C.N, Van Zanten R.H, Timing of protein Intake and clinical outcome of adult critically ill patients on prolonged mechanical ventilation: The PROTINVENT retrospective study. Journal of Clinical Nutrition, Vol 38 (2), April 2019: 883-890.

21. Bonten MJ, Gaillard CA, Van de Hulst, et al. Intermittent enteral feeding: the influence on respiratory and digestive tract colonization in mechanically ventilated intensive care unit patients. Am J Respir Crit Care Med 1996;154 (2, pt 1): 394 - 399.

22. Stevens EC, Lipscomb AF, Poole GV, Sacks GS. Comparison of continuous vs intermittent nasogastric enteral feeding in trauma patients: perceptions and practice. Nutr Clin Pract. 2002; 17(2): 118-122

23. MacLeoad J.B., Lefton J., Houghton D., Roland C., Doherty J., Cohn S.M., Barquist E.S., Prospective randomised control trial of intermittent versus continuous gastric feeds for critically ill trauma patients. Journal of Trauma, Vol 63 (1), 2007: p57-61

24. Evan D.C., Forbes R., Jones C., Cotterman R., Njoku C., Tulman D., Bergese S.D, Thomas D., Papadimos T.J., Stawicki S.P., Continuous vs bolus tube feeds: Does the modality affect glycemic variability, tube feeding volume, caloric intake or insulin utilization. International Journal of Critical Illness and Injury Science, Vol 6 (1), Jan - Mar 2016: 9 15.

25. Cadell KA, Martindale R, McClave SA, Miller K. Can the intestinal dysfunction of critical illness be differentiated from postoperative ileus? Curr Gastroenterol Rep 2011;13(4):358367

26. Khoshoo V, Brown S. Gastric emptying of two whey-based formulas of different energy density and its clinical implication in children with volume intolerance. Eur J Clin Nutr 2002; 56:656-8

27. Braunschweig $C L$, Levy $P$, Sheean $P M$, Wang $X$. Enteral compared with parenteral nutrition: a meta-analysis. Am J Clin Nutr. 2001;74(4):543 $-542$

28. Peter JV, Moran JL, Philips-Hughes J. A metaanalysis of treatment outcomes of early enteral versus early parenteral nutrition in hospitalized patients. Crit Care Med. 2005;33 (1):213-220 